Original Article

\title{
Perilaku Pencegahan Stunting pada Ibu Hamil
}

\author{
Stunting Preventive Behavior during Pregnancy
}

\section{Nurfatimah*, Priska Anakoda, Kadar Ramadhan, Christina Entoh, Sony Bernike Magdalena Sitorus, Lisda Widianti Longgupa}

\author{
Prodi D-III Kebidanan Poso, Poltekkes Kemenkes Palu
}

(*nfatimahhh@gmail.com)

\begin{abstract}
ABSTRAK
Pencegahan stunting mulai dari awal kehamilan harus dilakukan agar dapat menurunkan kejadian stunting pada anak. Kejadian stunting dapat terjadi pada masa kehamilan dikarenakan asupan gizi yang kurang saat hamil, pola makan yang tidak sesuai, serta kualitas makanan yang rendah sehingga mengakibatkan terhambatnya pertumbuhan. Tujuan penelitian untuk mengetahui gambaran perilaku ibu hamil dalam mencegah stunting pada balita di wilayah kerja Puskesmas Mapane. Desain Penelitian ini cross-sectional. Populasi penelitian adalah ibu hamil trimester II yang ada di wilayah kerja Puskesmas Mapane, berjumlah 49 orang. Teknik sampling yang digunakan adalah total sampling. Hasil Penelitian menunjukan bahwa $53.1 \%$ responden yang memiliki perilaku yang baik dalam pencegahan stunting. Hasil uji bivariat menunjukan umur $>35$ tahun $(\mathrm{p}=0,026)$, pendidikan perguruan tinggi $(\mathrm{p}<0,001)$, ibu bekerja ( $\mathrm{p}<0,001)$, dan Multigravida $(\mathrm{p}=0,036)$ berhubungan dengan perilaku baik dalam pencegahan stunting. Kesimpulan dari penelitian ini adalah perilaku ibu hamil yang baik dalam pencegahan stunting berada pada usia >35 tahun, pada tingkat pendidikan perguruan tinggi, pada ibu yang bekerja dan multigravida.
\end{abstract}

Kata kunci : Stunting; perilaku; gravida; umur; pendidikan

\section{ABSTRACT}

Prevention of stunting starting from the beginning of pregnancy must be done in order to reduce the incidence of stunting in children. Incidence of stunting can occur during pregnancy due to inadequate nutritional intake during pregnancy, inappropriate eating patterns, and low food quality resulting in stunted growth. The purpose of the study was to describe the behavior of pregnant women in preventing stunting in toddlers in the working area of the Mapane Health Center. This study was cross-sectional. The population in this study was the second trimester pregnant women in the working area of the Mapane Health Center, amounting to 49 people. The sampling technique used is total sampling. The results showed that $53.1 \%$ of respondents had good behavior in preventing stunting. The results of the bivariate test showed that age $>35$ years $(p=0.026)$, college education $(p<0.001)$, working mother $(p<0.001)$, and multigravida $(p=0.036)$ were associated with good behavior in stunting prevention. The conclusion of this study is that the behavior of pregnant women who are good in preventing stunting is at the age of $>35$ years, at the college education level, in working mothers and multigravida.

Keywords : Stunting; behavior; gravida; age; education

https://doi.org/10.33860/jik.v15i2.475 


\section{PENDAHULUAN}

Stunting adalah kondisi dimana panjang badan atau tinggi badan yang tidak sesuai atau tidak mencapai (kurang) jika dibandingan dengan umur. Sesuai dengan stadar pertumbuhan anak menurut WHO kondisi stunting adalah kondisi yang jika di ukur panjang atau tinggi badan kurang dari minus dua standar deviasi (-2SD). Bebarapa faktor seperti kondisi sosial ekonomi, gizi ibu saat hamil, kesakitan pada bayi, juga kurangnya kondisi saat bayi dapat menjadi penyebab dari kejadian stunting ini. ${ }^{1}$ Stunting adalah suatu permasalahan gizi yang ada di negara miskin dan berkembang. Kondisi ini menjadi sebuah permasalahan gizi karena dapat meningkatkan risiko terjadinya kesakitan dan kematian, perkembangan otak sub-optimal sehingga terlambatnya perkembangan motorik. ${ }^{2}$

Stunting adalah masalah gizi yang bersifat kronis karena menjadi salah satu keadaan malnutrisi yang memiliki hubungan dengan tidak tercukupinya zat gizi dimasa lalu. Pengukuran stunting sendiri dilakukan dengan memperhatikan tinggi atau panjang badan, umur dan jenis kelamin balita. Kondisi stunting ini sulit disadari di masyarakat karena kebiasaan tidak Kebiasaan tidak mengukur tinggi atau panjang badan balita. Karena hal ini stunting adalah salah satu fokus untuk target perbaikan gizi di dunia. ${ }^{3}$

Di tahun 2017 balita yang mengalami stunting di dunia sebesar 22,2\% atau sekitar 150 juta. Angka ini mengalami penurunan jika dibandingkan pada tahun 2016 yaitu sebesar 22,9\%. Tahun 2017 sekitar 55\% balita stunting di dunia berada di Asia dan sekitar 39\% berada di Afrika. Balita stunting di Asia dari 83 juta proporsi terbanyak berasal dari Asia Selatan 58,7\% dan proporsi paling sedikit di Asia Tengah $0,9 \%$. Sementara itu, di Asia Tenggara proporsi balita stunting 29,4\%. Berdasarkan Pemantauan Status Gizi (PSG) Prevalensi balita pendek dari tahun 2016 yaitu 27,5\% menjadi 29,6\% pada tahun 2017. ${ }^{1}$ Pada tahun 2018 persentasi balita Stunting di Indonesia adalah 30,8\%. Dimana posisi persentasi paling tertinggi balita stunting di Indonesia terdapat di Provinsi Nusa Tenggara Timur dan paling rendah terdapat di DKI Jakarta ${ }^{4}$.

Di Sulawesi Tengah pada tahun 2018 prevalensi Stunting adalah $32,3 \%$ dimana prevalensi tertinggi berada di Kabupaten Donggala sebesar $34,9 \%$ dan yang paling rendah berada di kabupaten Buol yaitu sebesar 9,4\%. Di Kabupaten Poso, prevalensi stunting tahun 2018 menurun menjadi 26,2\% dari 39,4\% tahun 2013.5,6 Namun studi lain yang pernah dilakukan di salah satu kecamatan menunjukan prevalensi stunting masih diatas 30\%.7 Di wilayah kerja Puskesmas Mapane tahun 2017 jumlah balita Stunting mencapai 95 orang dari jumlah balita 495 orang $(19,1 \%)$, tahun 2018 jumlah balita Stunting masih sama dari tahun sebelumnya. Pada tahun 2019 jumlah balita Stunting adalah mencapai 160 orang dari jumlah balita 938 orang $(17,0 \%) .{ }^{8}$

Perbaikan gizi dan kesehatan remaja, calon pengantin (catin), ibu hamil (bumil), ibu nifas (bufas) serta anak balita termasuk PAUD adalah beberapa cara pencegahan stunting dan dapat dilakukan dengan cara pendekatan gizi dan non gizi. Oleh karena itu perlu adanya penguatan dan perluasan mengenai intervensi gizi sensitive dan spesifik terkait stunting (air, pangan, sanitasi, pendidikan, infrastruktur, akses pelayanan dan ekonomi). ${ }^{9,10}$

Kejadian stunting dapat terjadi pada masa kehamilan dikarenakan asupan gizi yang kurang saat hamil, pola makan yang tidak sesuai, serta kualitas makanan yang rendah sehingga mengakibatkan terhambatnya pertumbuhan. Keterkaitan antara tingkat pendidikan, pengetahuan serta sikap dalam memenuhi zat gizi selama mengandung dengan perbaikan gizi dan kesehatan ibu hamil. Karena kurangnya pengetahuan dan praktik yang tidak tepat sehingga mejadi hambatan dalam peningkatan gizi karena pada umumnya banyak orang yang tidak tahu tentang gizi selama kehamilan dan dua tahun pertama kehidupan sangat penting bagi pertumbuhan kedepennya. ${ }^{2}$

Pencegahan stunting sendiri sudah dilakukan yaitu dari masa kehamilan seorang ibu terutama sejak 1000 Hari Pertama Kehidupan (HPK) satu diantaranya dengan meningkatkan pengetahuan ibu tentang sikap dan perilaku seorang ibu dalam mencegah stunting. Dalam meningkatkan pengetahuan dan sikap ibu tentang kesehatan dan gizi perlunya paket gizi, yaitu pemberian makanan tambahan, vitamin A, dan tablet tambah darah pada ibu hamil dan balita, dan memahami tentang pengasuhan yang tepat. ${ }^{11}$

Salah satu program pencegahan stunting adalah dengan pendekatan keluarga misalnya dengan melakukan kunjungan ANC secara rutin (K1-K4) yang diterapkan oleh puskesmas. Karena stunting bisa dicegah mulai dari ibu 
mengandung sehingga kunjungan ANC sangat penting untuk mendeteksi dan mencegah faktor risiko terjadinya stunting dengan cara memberikan pelayanan tentang status kesehatan ibu, imunisasi, gizi dan konseling menyusui. ${ }^{12}$ Pencegahan stunting mulai dari masa kehamilan sangat penting dilakukan agar dapat menekan prevalensi stunting.

Penelitian ini bertujuan untuk mengetahui gambaran perilaku ibu hamil dalam mencegah stunting pada balita di wilayah kerja Puskesmas Mapane.

\section{METODE PENELITIAN}

Jenis penelitian ini merupakan penelitian deskriptif yaitu penelitian diarahkan untuk mendeskripsikan atau menguraikan suatu keadaan di dalam suatu komunitas atau masyarakat secara objektif yaitu perilaku ibu hamil dalam mencegah stunting pada balita di wilayah kerja Puskesmas Mapane. Penelitian ini dilaksanakan di posyandu wilayah kerja Puskesmas Mapane pada bulan Februari-Maret 2021.

Populasi dalam penelitian ini adalah ibu hamil trimester II yang ada di Wilayah Kerja Puskesmas Mapane yaitu sebanyak 49 ibu hamil.Teknik pengambilan sampel dalam penelitian ini menggunakan metode Purposive sampling. Jumlah sampel dalam penelitian ini adalah sebanyak 49 responden.

Definisi operasional merupakan definisi yang membatasi ruang lingkup atau pengertian variabel-variabel yang diamati dan diteliti ${ }^{13}$.

Variabel dependen dalam penelitian ini adalah perilaku pencegahan stunting oleh ibu hamil. Perilaku yang dilakukan ibu hamil sehati-hari yang brkaitan dnegan pencegahan stunting yaitu pemeriksaan ANC, konsumsi Fe, kebutuhan nutrisi, dan mengindari paparan asap rokok. Perilaku dikatakan baik jika skor $\geq 80$, dan kurang jika $<80$. Variabel karakteristik ibu terdiri atas umur: $<20$ tahun, $20-35$ tahun, dan $>35$ tahun, pendidikan: SD, SMP, SMA, dan Perguruan Tinggi; pekerjaan: bekerja dan tidak bekerja; gravida: primigravida, multigravida, dan grandemultigravida.

Metode pengumpulan data yang akan peneliti gunakan adalah pengumpulan data primer dengan menggunakan kuesioner. Data primer adalah data yang diperoleh langsung dari subjek penelitian dengan menggunakan alat pengukuran atau alat pengambilan data langsung pada subjek sebagai sumber informasi yang dicari. ${ }^{14}$

Data didapatkan secara langsung dari responden yaitu dengan membagikan kuesioner dan meminta responden untuk menjawab sesuai sikap ibu hamil yang hamil yang datang ke posyandu wilayah kerja puskesmas mapane. Pengumpulan data menggunakan aplikasi Kobocollect. Kuesioner penelitian ini dapat dilihat pada tautan berikut: https://ee.kobotoolbox.org/preview/eKhNcynp

Kuesioner perilaku menggunakan skala likert. Terdiri dari 18 pernyataan positif dan 2 pernyataan negatif. Kriteria penilaian pada pernyataan positif yaitu nilai 0 untuk tidak pernah dilakukan, nilai 1 kadang dilakukan, nilai 2 untuk selalu dilakukan. Penilaian untuk pertanyaan negatif yaitu 0 jika selalu dilakukan, nilai 1 untuk kadang dilakukan, nilai 2 untuk tidak pernah dilakukan. Analisis data dalam penelitian ini adalah analisis univariat dan bivariat. Analisis bivariat menggunakan uji chi square.

$\underline{\text { Tabel } 1 \text { Distribusi Frekuensi Berdasarkan Umur, Pendidikan, Pekerjaan, Gravida dan Perilaku }}$

\begin{tabular}{cccc}
\hline Variabel & Kategori & Frekuensi & Persentase $(\%)$ \\
\hline Usia & $<20$ & 5 & 10.2 \\
& $20-35$ & 39 & 79,6 \\
& $>35$ & 5 & 10,0 \\
\hline Pendidikan & SD & 1 & 2.0 \\
& SMP & 9 & 18.4 \\
& SMA & 25 & 51.0 \\
& Pergururan Tinggi & 14 & 28.6 \\
\hline Pekerjaan & Bekerja & 11 & 22.4 \\
& Tidak Bekerja & 38 & 76.6 \\
\hline Gravida & Primigravida & 17 & 34.7 \\
& Multigravida & 30 & 61.2 \\
& Grandemultigravida & 2 & 4.1 \\
\hline Perilaku & Baik & 26 & 53.1 \\
& Kurang & 23 & 46.9
\end{tabular}

Sumber: Data Primer, 2021 


\section{HASIL}

Berdasarkan tabel 1 menunjukkan bahwa distribusi frekuensi berdasarkan usia terbanyak yaitu kategori umur 20-35 tahun dengan jumlah 39 responden $(79,6 \%)$, Pendidikan terbanyak yaitu kategori SMA dengan jumlah 25 responden $(51,0 \%)$, pekerjaan terbanyak yaitu kategori tidak bekerja dengan jumlah 38 responden $(38,2 \%)$, gravida terbanyak yaitu kategori multigravida dengan jumlah 30 responden $(61,2 \%)$ dan perilaku terbanyak yaitu kategori baik dengan jumlah 26 responden (53.06\%), kurang sebanyak 23 responden (46.94\%).

\section{Tabel 2 Distribusi frekuensi Perilaku Hamil dalam Mencegah Stuting pada Balita Wilayah Kerja Puskesmas Mapane Tahun 2021}

Pemeriksaan ANC

\section{Perilaku Ibu}

\begin{tabular}{ccrrrr}
\multicolumn{2}{c}{ Selalu } & \multicolumn{2}{c}{ Kadang } & \multicolumn{2}{c}{ Tidak pernah } \\
\hline $\mathbf{n}$ & $\%$ & $\mathbf{n}$ & $\%$ & $\mathbf{n}$ & $\%$
\end{tabular}

Datang ke bidan desa untuk memeriksakan kehamilan (pemeriksaan Tekanan darah, Hb, pengukuran berat badan, dan pengukuran lingkar lengan) sesuai saran dari bidan.

\begin{tabular}{|c|c|c|c|c|c|c|}
\hline $\begin{array}{l}\text { Ketika datang memeriksakan kehamilan selalu bertanya } \\
\text { kepada bidan tentang keluhan yang dialami. }\end{array}$ & 32 & 65.3 & 12 & 24.5 & 5 & 10.2 \\
\hline Hadir saat ada posyandu. & 22 & 44.9 & 26 & 53.1 & 1 & 2.0 \\
\hline $\begin{array}{l}\text { Datang Memeriksakan kehamilan di tiga bulan pertama } \\
\text { minimal } 1 \text { kali. }\end{array}$ & 36 & 73.5 & 0 & 0 & 13 & 26.5 \\
\hline $\begin{array}{l}\text { Saat tidak hadir melaksanakan posyandu, datang ke bidan } \\
\text { untuk memeriksakan kehamilannya. }\end{array}$ & 21 & 42.9 & 15 & 30.6 & 13 & 26.5 \\
\hline
\end{tabular}

untuk memeriksakan kehamilannya.

\begin{tabular}{|c|c|c|c|c|c|c|}
\hline Mengonsumsi buah untuk menambah asupan gizi. & 48 & 98.0 & 1 & 2.0 & 0 & 0 \\
\hline Selama hamil selalu minum susu untuk ibu hamil. & 22 & 44.9 & 16 & 32.7 & 11 & 22.4 \\
\hline $\begin{array}{l}\text { Mengonsumsi ikan dan olahan kacang-kacangan seperti } \\
\text { tahu dan tempe. }\end{array}$ & 45 & 91.8 & 4 & 8.2 & 0 & 0 \\
\hline Tidak mengonsumsi sayuran karena tidak suka. & 3 & 6.1 & 37 & 75.5 & 9 & 18.4 \\
\hline $\begin{array}{l}\text { Menggunakan garam yang mengandung yodium untuk } \\
\text { mengolah makanan sehari-hari. }\end{array}$ & 48 & 98.8 & 1 & 2.0 & 0 & 0 \\
\hline \multicolumn{7}{|l|}{ Konsumsi Zat Besi } \\
\hline Mengonsumsi setiap tablet Fe yang diberikan oleh bidan. & 36 & 73.5 & 13 & 26.5 & 0 & 0 \\
\hline $\begin{array}{l}\text { Mengonsumsi kacang hijau untuk menambah asupan zat } \\
\text { besi. }\end{array}$ & 39 & 79.6 & 3 & 6.1 & 7 & 14.3 \\
\hline $\begin{array}{l}\text { Pergi ke bidan ketika merasakan gejala sering pusing, cepat } \\
\text { lelah dan merasa lemah. }\end{array}$ & 33 & 63.7 & 5 & 10.2 & 11 & 22.4 \\
\hline Tablet Fe di konsumsi dengan susu. & 5 & 10.2 & 0 & 0 & 44 & 89.8 \\
\hline $\begin{array}{l}\text { Mengonsumsi sayuran yang mengandung zat besi seperti } \\
\text { sayuran hijau. }\end{array}$ & 6 & 12.2 & 43 & 87.8 & 0 & 0 \\
\hline \multicolumn{7}{|l|}{ Menghindari Paparan Asap Rokok } \\
\hline $\begin{array}{l}\text { Ketika di rumah jika ada orang yang sedang merokok saya } \\
\text { selalu menghindarinya. }\end{array}$ & 30 & 61.2 & 19 & 38.8 & 0 & 0 \\
\hline $\begin{array}{l}\text { Ketika berada di luar rumah menggunakan masker untuk } \\
\text { menghindari paparan asap rokok. }\end{array}$ & 26 & 53.1 & 23 & 46.9 & 0 & 0 \\
\hline $\begin{array}{l}\text { Ketika berada di dalam rumah jika ada orang yang merokok } \\
\text { menyuruh untuk merokok diluar. }\end{array}$ & 21 & 42.9 & 12 & 24.5 & 16 & 32.7 \\
\hline $\begin{array}{l}\text { Menyarankan pada anggota keluarga yang merokok untuk } \\
\text { mengurangi merokok. }\end{array}$ & 28 & 57.1 & 14 & 28.6 & 7 & 14.3 \\
\hline $\begin{array}{l}\text { Menghidari tempat perkumpulan orang yang sedang } \\
\text { merokok }\end{array}$ & 36 & 73.5 & 13 & 26.5 & 0 & 0 \\
\hline
\end{tabular}

Berdasarkan tabel 2 menunjukan untuk pemeriksaan ANC sebanyak $83.7 \%$ perilaku ibu yang selalu datang ke bidan desa untuk memeriksakan kehamilan (pemeriksaan
Tekanan darah, $\mathrm{Hb}$, pengukuran berat badan, dan pengukuran lingkar lengan) sesuai saran dari bidan namun, sekitar $53.1 \%$ perilaku ibu hamil yang kadang hadir saat ada posyandu. 
Perilaku ibu dalam pemenuhan kebutuhan nutrisi sekitar 98.8 ibu yang menggunakan garam yang mengandung yodium untuk mengolah makanan sehari-hari. Tetapi, sebayak $75.5 \%$ perilaku ibu hamil yang kadang tidak mengonsumsi sayuran karena tidak suka.

Perilaku ibu dalam mengonsumsi zat besi asekitar $79.6 \%$ perilaku ibu yang selalu mengonsumsi kacanng kacang hijau untuk menambah asupan zat besi dan sebanyak 89.8\% ibu yang memiliki perilaku tidak pernah mengonsumsi tablet Fe dengan susu.

Perilaku ibu menghindari paparan asap rokok, sebanyak $73.5 \%$ perilaku ibu yang menghindari tempat perkumpulan orang yang sedang merokok. Tetapi, sebanyak $32.7 \%$ perilaku ibu ibu yang ketika berada dirumah jika ada orang yang merokok tidak pernah menyuruh untuk merokok di luar .

Tabel 3 menunjukan bahwa $80 \%$ ibu yang berumur $>35$ tahun memiliki perilaku yang baik dalam pencegahan stunting sedangkan $100 \%$ responden berusia $<20$ tahun memiliki perilaku yang kurang baik dalam pencegahan stunting. Hasil uji chi square diperoleh nilai $\mathrm{p}=0,026$, hal ini membuktikan bahwa ada hubungan antara umur dengan perilaku pencegahan stunting pada ibu hamil. Berdasarkan variabel pendidikan, $100 \%$ ibu yang berpendidikan perguruan tinggi memiliki perilaku yang baik dalam pencegahan stunting sedangkan $100 \%$ responden berpendidikan SD memiliki perilaku yang kurang baik dalam pencegahan stunting. Hasil uji chi square diperoleh nilai $\mathrm{p}<0,001$, hal ini membuktikan bahwa ada hubungan antara pendidikan dengan perilaku pencegahan stunting pada ibu hamil.

Tabel 3 menunjukan bahwa 100\% ibu yang bekerja memiliki perilaku yang baik dalam pencegahan stunting sedangkan $60,5 \%$ ibu yang tidak bekerja memiliki perilaku yang kurang baik dalam pencegahan stunting. Hasil uji chi square diperoleh nilai $\mathrm{p}<0,001$, hal ini membuktikan bahwa ada hubungan antara pekerjaan dengan perilaku pencegahan stunting pada ibu hamil. Berdasarkan variabel gravida, $66,7 \%$ ibu multigravida memiliki perilaku yang baik dalam pencegahan stunting sedangkan $100 \%$ ibu grandemultigravida memiliki perilaku yang kurang baik dalam pencegahan stunting. Hasil uji chi square diperoleh nilai $\mathrm{p}=0,036$, hal ini membuktikan bahwa ada hubungan antara gravida dengan perilaku pencegahan stunting pada ibu hamil.

Tabel 3 Distribusi Frekuensi berdasarkan Usia, Pendidikan, Pekerjaan, Gravida terhadap Perilaku Ibu Hamil dalam Mencegah Stunting pada Balita di Wilayah Kerja Puskesmas Mapane

\begin{tabular}{|c|c|c|c|c|c|c|c|}
\hline \multirow[b]{3}{*}{ Variabel } & \multicolumn{6}{|c|}{ Perilaku Pencegahan stunting } & \multirow{3}{*}{ Nilai $p$} \\
\hline & \multicolumn{2}{|c|}{ Baik } & \multicolumn{2}{|c|}{ Kurang } & \multicolumn{2}{|c|}{ Jumlah } & \\
\hline & $\mathbf{n}$ & $\%$ & $\mathbf{n}$ & $\%$ & $\mathbf{n}$ & $\%$ & \\
\hline \multicolumn{8}{|l|}{ Usia } \\
\hline$<20$ tahun & 0 & 0 & 5 & 100 & 5 & 100 & 0,026 \\
\hline 20-35 tahun & 22 & 56.4 & 17 & 43.6 & 39 & 100 & \\
\hline$>35$ tahun & 4 & 80.0 & 1 & 20.0 & 5 & 100 & \\
\hline \multicolumn{8}{|l|}{ Pendidikan } \\
\hline SD & 0 & 0 & 1 & 100 & 1 & 100 & $<0,001$ \\
\hline SMP & 2 & 22.2 & 7 & 77.8 & 9 & 100 & \\
\hline SMA & 10 & 40.0 & 15 & 60.0 & 25 & 100 & \\
\hline PT & 14 & 100 & 0 & 0 & 14 & 100 & \\
\hline \multicolumn{8}{|l|}{ Pekerjaan } \\
\hline Kerja & 11 & 100 & 0 & 0 & 11 & 100 & $<0,001$ \\
\hline Tidak kerja & 15 & 39.5 & 23 & 60.5 & 38 & 100 & \\
\hline \multicolumn{8}{|l|}{ Gravida } \\
\hline Primigravida & 6 & 35.3 & 11 & 64.7 & 17 & 100 & 0,036 \\
\hline Multigravida & 20 & 66.7 & 10 & 33.3 & 30 & 100 & \\
\hline Grandemultigravida & 0 & 0 & 2 & 100 & 2 & 100 & \\
\hline
\end{tabular}

\section{PEMBAHASAN}

Karakteristik dan sosiodemografi ibu berhubungan dengan perilaku pencegahan stunting. Hasil penelitian ini menunjukan responden yang baik perilaku pencegahan stuntingnya adalah berumus >35 tahun. Semakin cukup umur, tingkat keterampilan fisik dan kekuatan seseorang akan lebih matang dalam menyerap informasi, berfikir dan 
bekerja. ${ }^{15}$ Dalam aspek pendidikan, ibu yang telah menempuh pendidikan tinggi lebih baik dalam pencegahan stunting. Pendidikan dianggap dapat mempengaruhi perilaku seseorang, dapat meningkatkan peran aktif dalam kegiatan posyandu dan berperilaku, bertindak, dan bersikap untuk mendorong perilaku kesehatan. ${ }^{16}$ Perilaku pencegahan stunting lebih paik pada ibu bekerja. Peluang ibu yang bekerja untuk memperoleh informasi lebih baik dibanding yang tidak berkerja, namun studi terdahulu menyebutkan ibu yang bekerja lebih berisiko mengalami anak yang stunting. ${ }^{17,18}$ Perilaku pencegahan stunting lebih baik pada ibu multigravida. Sebuah penelitian menunjukan bahwa adanya hubungan antara jumlah kehamilan dengan perilaku ibu. Ibu primigavida cenderung memiliki perilaku yang kurang karena belum memiliki pengalaman untuk kehamilan berbeda dengan ibu multigravida. Namun, pada ibu grandemultigravida cenderung memiliki perilaku yang kurang dikarenakan biasanya ibu yang sudah memiliki 5 anak akan sibuk mengurus anaknya sehingga dalam perilaku pencegahan stunting akan memiliki sikap yang kurang. ${ }^{12}$

Temuan penelitian ini menunjukan bahwa perilaku ibu hamil dalam pencegahan stunting yang baik masih rendah, hanya $53,1 \%$. Hal ini mengindikasikan bahwa penerapan 1000 HPK saat hamil masih kurang baik. Hal yang cukup menggembirakan adalah $83,7 \%$ responden selalu datang memeriksakan kehamilannya kepada bidan desa, namun sekitar $53.1 \%$ perilaku ibu hamil yang kadang hadir saat ada posyandu. Ibu lebih nyaman melakukan pemeriksaan langsung ke rumah bidan dibanding harus ke posyandu. Hal ini bisa terkait dengan pekerjaan dan juga situasi pandemik Covid-19. Masa pandemik Covid-19 dikhawatirkan dapat mengganggu pelayanan ANC pada ibu hamil karena pelayanan posyandu ditiadakan. ${ }^{19,20}$ Olehnya itu peran bidan desa sangat penting.

Keaktifan ibu hamil dalam melakukan pemeriksaan ANC adalah hal yang penting. ANC penting untuk untuk menilai keadaan kesehatan ibu dan janin pada awal kehamilan, mencegah komplikasi yang tidak diinginkan selama kehamilan, mencegah kematian ibu dan anak, meningkatkan kesehatan ibu dan bayinya, untuk membina hubungan suami, istri dan anak yang baik. Asuhan antenatal mendorong interaksi keluarga dan ikatan antara suami, istri dan bayi mereka. ${ }^{21,22}$

Status gizi ibu hamil, bahkan sebelum hamil akan menentukan pertumbuhan janin. sehingga pemeriksaan ANC merupakan salah satu pencegahan stunting. ${ }^{23}$ Dalam hal pemenuhan nutrisi, hasil temuan penelitian menunjukan $98 \%$ ibu mengonsumsi buah untuk menambah asupan gizi, 91,8\% mengonsumsi ikan dan olahan kacang-kacangan, dan mayoritas sudah menggunakan garam beryodium. Untuk konsumsi tablet Fe, masih banyak yang belum disiplin dimana hanya $73,5 \%$ yang selalu mengonsumsi tablet Fe. Asupan nutrisi ibu yang kurang baik selama kehamilan dapat menyebabkan asupan nutrisi untuk janin tidak mencukupi. Akibat gizi yang tidak tercukupi dapat berpengaruh pada pertumbuhan janin dan bisa terus berlanjut setelah kelahiran. ${ }^{24}$ Oleh karena itu, Kebutuhan nutrisi yang baik bagi ibu hamil sangat penting. ${ }^{25}$

Melahirkan anak dengan berat badan normal atau tidak BBLR adalah antisipasi berikutnya untuk mencegah anak stunting. Anemia merupakan salah satu penyebab BBLR yang diakibatkan oleh kekurangan zat besi. Konsumsi tablet $\mathrm{Fe}$ sangat penting selama kehamilan untuk meningkatkan asupan besi sehingga dapat menurunkan kejadian anemia pada ibu hamil. Hal ini tentu secara tidak langsung dapat mencegah stunting. ${ }^{26,27}$

Beberapa studi terdahulu menemukan bahwa paparan asap rokok baik pada saat hamil maupun setelah lahir dapat menyebabkan efek jangka panjang pada pertumbuhan tinggi badan anak sehingga dapat menyebabkan stunting pada anak. ${ }^{28-30}$ Dalam studi ini, mayoritas responden tinggal dengan angggota keluarga yang merokok. Perilaku ibu hamil dalam menghindari paparan asap rokok masih belum baik, hanya $42,9 \%$ yang selalu menyuruh untuk merokok di luar rumah, $57,1 \%$ menyarankan anggota keluarga untuk mengurangi merokok. Hal yang cukup menggembirakan adalah terdapat $73,5 \%$ yang selalu menghindari termpat yang ada orang merokok. Tetapi, sebanyak $32.7 \%$ perilaku ibu yang ketika berada dirumah jika ada orang yang merokok tidak pernah menyuruh untuk merokok di luar. Responden mengatakan bahwa sudah sering menegur suami untuk tidak merokok di dalam rumah namun kadang suami tidak mendengarkan sehingga responden yang memilih untuk menghindari. 
Paparan asap rokok dapat menyebabkan bayi lahir premature dan BBLR. Sebagai perokok pasif, ibu hamil dapat berisiko mengalami abortus, solusio plasenta, plasenta previa, insufisiensi plasenta, kelahiran premature, dan kecacatan pada janin. ${ }^{31-33}$ Anak sebagai perokok pasif juga berisiko untuk terkena dampak yang sama dengan para perokok aktif. ${ }^{34}$ Oleh karena itu menghindari paparan asap rokok termasuk dalam perilaku pencegahan stunting ${ }^{35}$.

Temuan penelitian ini dapat memberikan informasi kepada ibu hamil bahwa pencegahan stunting dimulai dari 1000 HPK atau pada saat hamil sangat penting sehingga bisa melahirkan anak yang sehat dan cerdas. Keterbatasan dalam penelitian ini dikarenakan situasi pandemi covid-19 para ibu hamil jarang datang ke posyandu sehingga proses pengumpulan datanya harus door-to-door.

\section{KESIMPULAN DAN SARAN}

Dari hasil penelitian menunjukkan bahwa perilaku ibu hamil yang baik dalam pencegahan stunting usia $>35$ tahun sebesar $80 \%$, pada tingkat pendidikan terbanyak yaitu kategori perguruan tinggi sebesar $100 \%$, kategori pekerjaan terbanyak yaitu ibu yang bekerja sebesar 100\%, dan berdasarkan gravida terbanyak yaitu multigravida sebesar $66.7 \%$. Peneliti menyarankan kepada petugas yaitu bidan desa agar kegiatan penyuluhan pada ibu hamil tentang perilaku pencegahan stunting pada balita melalui posyandu ataupun kunjungan ANC dilakukan secara periodik dan berkesinambungan.

\section{DAFTAR PUSTAKA}

1. Kemenkes RI. Buletin Stunting. Kementeri Kesehat RI. 2018;301(5):1163-78.

2. BAPPENAS, UNICEF. Laporan Baseline SDG tentang Anak-Anak di Indonesia. 2017 p. $1-105$.

3. Mayasari D, Indriyani R, Ikkom B, Kedokteran F, Lampung U, Tanjungkarang PK, et al. Stunting, Faktor Risiko dan Pencegahannya Stunting, Risk Factors and Prevention. J Kesehat dan Agromedicine. 2018;5:540-5.

4. Kemenkes RI. Profil Kesehatan Indonesia. Vol. 53. Jakarta; 2019. 1689-1699 p.

5. Kementerian Kesehatan R.I. Laporan Riskesdas 2018 Provinsi Sulawesi Tengah. Jakarta: Badan Penelitian dan Pengembangan Kesehatan, Kementerian Kesehatan R.I; 2018. 399 p.

6. Kementerian Kesehatan R.I. Riskesdas dalam Angka Provinsi Sulawesi Tengah Tahun 2013. Jakarta: Badan Penelitian dan Pengembangan Kesehatan; 2013.

7. Ramadhan K. Status Gizi menurut Tinggi Badan per Umur pada Balita. Poltekita J Ilmu Kesehat. 2019;13(2):96-101.

8. Puskesmas Mapane. Rekamedik Puskesmas Mapane. Mapane; 2020.

9. Arsyati AM. Pengaruh Penyuluhan Media Audiovisual Dalam Pengetahuan Pencegahan pada Ibu Hamil di Desa Cibatok 2 Cibungbulang. J Mhs Kesehat Masy. 2019;2(3):182-90.

10. Hafid F, Taqwin T, Linda L, Nasrul N, Ramadhan K, Bohari B. Specific Interventions to Prevent Stunting in Children Under 2 Years after the Natural Disaster. Open Access Maced J Med Sci [Internet]. 2021 Feb 12;9(E):64-9. Available from: https://oamjms.eu/index.php/mjms/article/v iew/5677

11. Arnita S, Rahmadhani DY, Sari MT. Hubungan Pengetahuan dan Sikap Ibu dengan Upaya Pencegahan Stunting pada Balita di Wilayah Kerja Puskesmas Simpang Kawat Kota Jambi. J Akad Baiturrahim Jambi. 2020;9(1):7.

12. Salamung N, Haryanto J, Sustin F. FaktorFaktor yang Berhubungan dengan Perilaku Pencegahan Stunting pada saat Ibu Hamil di Wilayah Kerja Puskesmas Grujuga Kabupaten Bondowoso. 2019;10(5):264-9.

13. Notoatmodjo S. Meditologi Penelitian Kesehatan. Jakarta: Rineka Cipta; 2010.

14. Machfoedz I. Metodologi penelitian kuantitatif dan kualitatif bidang kesehatan, keperawatan, kebidanan, kedokteran. Makasar: Fitramaya; 2010.

15. Purnamasari H, Shaluhiyah Z, Kusumawati A. Pelatihan Kader Posyandu Sebagai Upaya Pencegahan Stunting Pada Balita di Wilayah Kerja Puskesmas Margadana dan Puskesmas Tegal Selatan Kota Tegal. J Kesehat Masy. 2020;8(3):432-9.

16. Alifah AP. Faktor-Faktor yang Berhubungan dengan Tingkat Partisipasi Ibu Balita dalam Kegiatan Posyandu di Wilayah Kerja Puskesmas Cibeureum Kota Cimahi. Politek Kesehat Kemenkes Bandung Jur Gizi Progr Stud Diploma 3. 2018;

17. Fikadu T, Assegid S, Dube L. Factors associated with stunting among children of age 24 to 59 months in Meskan district, Gurage Zone, South Ethiopia: A casecontrol study. BMC Public Health. 2014;14(1):1-7.

18. Habimana S, Biracyaza E. $\langle$ p $>$ Risk Factors Of Stunting Among Children Under 5 Years Of Age In The Eastern And Western 
Provinces Of Rwanda: Analysis Of Rwanda Demographic And Health Survey 2014/2015</p >. Pediatr Heal Med Ther. 2019; Volume 10:115-30.

19. Mufarida B. Posyandu Vakum Selama Pandemi, Banyak Ibu Hamil Tak Dapat Pelayanan Memadai [Internet]. sindonews.com. 2020. Available from: https://nasional.sindonews.com/read/18233 8/15/posyandu-vakum-selama-pandemibanyak-ibu-hamil-tak-dapat-pelayananmemadai-1601532658

20. Efendi R. IBI: Pemeriksaan Kehamilan di Masa Pandemi COVID-19 Penting [Internet]. liputan6.com. 2020. Available from:

https://www.liputan6.com/regional/read/43 28866/ibi-pemeriksaan-kehamilan-di-masapandemi-covid-19-penting

21. Olarewaju R. Advantages of Antenatal Care [Internet]. Mother \& Child Hospital. 2020. Available from: https://motherandchildhospital.com/advanta ges-of-antenatal-care/

22. EBCOG Scientific Committee. The public health importance of antenatal care. Facts, views Vis ObGyn [Internet]. 2015;7(1):5-6. Available from: http://www.ncbi.nlm.nih.gov/pubmed/2589 7366

23. Martha E. Kajian Faktor Penyebab dan Intervensi Gizi Spesifik untuk Pencegahan Stunting di Kabupaten Lampung Utara. Jukema. 2019;5(2):413-25.

24. Candra A. Epidemiologi Stunting. semarang: Fakultas Kedokteran Universitas Diponegoro Semarang, 2020; 2020. 1-53 p.

25. Pratiwi IG. Edukasi Tentang Gizi Seimbang Untuk Ibu Hamil Dalam Pencegahan Dini Stunting. J Pengabdi Masy Sasambo. 2020;1(2):62.

26. Bingan S, Charla E. Hubungan Konsumsi Fe Dengan Panjang Badan Pada Anak Usia 1224 Bulan. Media Inf. 2020;15(2):115-20.

27. Ekayanthi NWD, Suryani P. Edukasi Gizi pada Ibu Hamil Mencegah Stunting pada Kelas Ibu Hamil. J Kesehat [Internet]. 2019;10(3):312. Available from: http://dx.doi.org/10.26630/jk.v10i3.1389

28. Quelhas D, Kompala C, Wittenbrink B, Han Z, Parker M, Shapiro M, et al. The association between active tobacco use during pregnancy and growth outcomes of children under five years of age: a systematic review and meta-analysis. BMC Public Health [Internet]. 2018 Dec 13;18(1):1372. Available from: https://bmcpublichealth.biomedcentral.com/ articles/10.1186/s12889-018-6137-7

29. Astuti DD, Handayani TW, Astuti DP.
Cigarette smoke exposure and increased risks of stunting among under-five children. Clin Epidemiol Glob Heal [Internet]. 2020 Sep;8(3):943-8. Available from: https://linkinghub.elsevier.com/retrieve/pii/ S2213398420300671

30. Muraro AP, Gonçalves-Silva RM V., Moreira NF, Ferreira MG, Nunes-Freitas AL, Abreu-Villaça Y, et al. Effect of tobacco smoke exposure during pregnancy and preschool age on growth from birth to adolescence: A cohort study. BMC Pediatr. 2014;14(1):1-9.

31. Ashford KB, Hahn E, Hall L, Rayens MK, Noland M, Ferguson JE. The Effects of Prenatal Secondhand Smoke Exposure on Preterm Birth and Neonatal Outcomes. J Obstet Gynecol Neonatal Nurs [Internet]. 2010 Sep;39(5):525-35. Available from: https://linkinghub.elsevier.com/retrieve/pii/ S0884217515303117

32. Stock SJ, Bauld L. Maternal smoking and preterm birth: An unresolved health challenge. PLOS Med [Internet]. 2020 Sep 14;17(9):e1003386. Available from: https://dx.plos.org/10.1371/journal.pmed.10 03386

33. Mojibyan M, Karimi M, Bidaki R, Rafiee P, Zare A. Exposure to Second-hand Smoke During Pregnancy and Preterm Delivery. Int J High Risk Behav Addict [Internet]. 2013 Feb 3;1(4). Available from: https://sites.kowsarpub.com/ijhrba/articles/ 19568.html

34. Mustika W, Syamsul D. Analisis Permasalahan Status Gizi Kurang Pada Balita di Puskesmas Teupah Selatan Kabupaten Simeuleu. J Kesehat Glob. 2018;1(3):127.

35. Kardila RV, Sumarmi M, Asrofin B, Kebidanan A, Mitra W, Nganjuk H, et al. Hubungan Keterpaparan Asap Rokok Selama Kehamilan dengan Berat Bayi Lahir. Kesehat Reproduksi. 2017;1(1):76-81. 